\title{
Erosão em entressulcos sob diferentes tipos de preparo e manejo do solo(1)
}

\author{
Elemar Antonino Cassol(2) e Vladimir Silva de Lima ${ }^{(3)}$
}

\begin{abstract}
Resumo - A validação de uso de modelos de predição da erosão hídrica do solo baseados em processos físicos fundamentais necessita de informações sobre os valores de seus parâmetros obtidos em condições locais. Este trabalho foi realizado no campo em um Argissolo Vermelho distrófico típico, com o objetivo de avaliar a erosão hídrica em entressulcos sem preparo do solo (com resíduos culturais na superfície), com preparo convencional com solo descoberto (sem resíduos) e com preparo convencional com resíduos incorporados. O esquema experimental baseou-se nos estudos realizados para a determinação da erodibilidade do solo em relação ao modelo WEPP (Water Erosion Prediction Project). Foi aplicada chuva simulada com intensidade planejada de $60 \mathrm{~mm} \mathrm{~h}^{-1}$, durante 70 minutos, e coletadas amostras da enxurrada das parcelas em entressulcos. A perda de solo em entressulcos foi significativamente menor no tratamento sem preparo do solo em relação aos tratamentos submetidos ao preparo convencional. As taxas de erosão e perda de água em entressulcos foram crescentes com o tempo de chuva até atingir um ponto de valor máximo, após o qual decresceram, com exceção do tratamento sem preparo do solo, cujas taxas foram crescentes em todo o período de aplicação da chuva. $\mathrm{O}$ valor da erodibilidade do solo em entressulcos é de $\mathrm{K}_{\mathrm{i}}=2,83 \times 10^{6} \mathrm{~kg} \mathrm{~s} \mathrm{~m}^{-4}$.
\end{abstract}

Termos para indexação: erodibilidade do solo em entressulcos, predição da erosão, erosão hídrica do solo, cultivo convencional.

\section{Interrill soil erosion under different tillage and management systems}

\begin{abstract}
The validation of soil water erosion models based on fundamentals physical processes needs information about the values of their parameters obtained under local conditions. A field study was carried out on a sandy clay loam Palleudult soil in order to evaluate the water erosion in interrill areas under the tillage and management soil systems of no tillage and conventional tillage on bare soil and on soil with residues incorporated. The experimental design was based on field experiments to determine soil erodibility using WEPP (Water Erosion Prediction Project) model. Simulated rainfall with intensity of about $60 \mathrm{~mm} \mathrm{~h}^{-1}$ was applied during 70 minutes and runoff samples were collected from the interrill plots. Interrill soil loss was significantly smaller in no-till treatment than in conventionally tilled treatments. Interrill erosion rates and water loss rates increased with the period of time of rain up to a maximum value and decreased after that, with the exception of no-till treatment where it increased during all rainfall period. The value of the soil interrill erodibility is $K_{\mathrm{i}}=2.83 \times 10^{6} \mathrm{~kg} \mathrm{~s} \mathrm{~m}^{-4}$.
\end{abstract}

Index terms: interril soil erodibility, erosion prediction, water erosion, conventional tillage.

\footnotetext{
(1) Aceito para publicação em 16 de agosto de 2002.

Parte da dissertação de mestrado apresentada pelo segundo autor à Universidade Federal do Rio Grande do Sul (UFRGS), Porto Alegre, RS. Financiado parcialmente pela Fapergs.

(2) UFRGS, Fac. de Agronomia, Dep. de Solos, Caixa Postal 776, CEP 90001-970 Porto Alegre, RS. Bolsista do CNPq. E-mail: cassolea@orion.ufrgs.br

(3) Instituto Nacional de Colonização e Reforma Agrária, Av. Loureiro da Silva, 515, CEP 90010-420 Porto Alegre, RS E-mail: vladimir@poa.incra.gov.br
}

\section{Introdução}

O processo de erosão hídrica envolve a desagregação de partículas do solo da sua massa original, o transporte dessas partículas (primárias ou agregados) e eventual deposição. Esse processo ocorre pela ação dos agentes erosivos, que são as gotas da chuva e o escoamento superficial da água sobre o solo (Ellison, 1946, 1947a, 1947b, 1947c, 1947d, 1947e; Ellison \& Ellison, 1947a, 1947b). 
Nos últimos 20 anos, foram desenvolvidos modelos de simulação da erosão hídrica baseados em processos físicos fundamentais, que têm fornecido estimativas consistentes da erosão (Meyer et al., 1975). Entre esses modelos, destaca-se o WEPP (Water Erosion Prediction Project), que surgiu com o objetivo de substituir a USLE a médio prazo (Lane et al., 1987). Nesse modelo, a erosão hídrica é separada em dois componentes: erosão em entressulcos e em sulcos (Flanagan et al., 1995).

Nos entressulcos, o impacto das gotas de chuva é o fator responsável pela desagregação das partículas da massa do solo, podendo desagregar grandes quantidades de partículas decorrentes da energia cinética das gotas, que exercem forças de pressão e cisalhamento no ponto de impacto. $\mathrm{O}$ transporte das partículas desagregadas é realizado, quase exclusivamente, pelo fluxo laminar raso, o qual é auxiliado em muito pela turbulência produzida pelo impacto das gotas de chuva, suspendendo e mantendo suspensas as partículas de solo (Foster et al., 1985).

A cobertura do solo apresenta efeito importante na erosão em entressulcos. Os resíduos vegetais na superfície do solo interceptam as gotas de chuva e dissipam a sua energia, evitando a desagregação das partículas e a formação de selo superficial. Além disso, há redução na velocidade da enxurrada e, conseqüentemente, redução na sua capacidade de desagregação e transporte de partículas do solo (Mannering \& Meyer, 1963). Braida \& Cassol (1999) determinaram redução exponencial da erosão em entressulcos com o aumento da cobertura do solo por resíduos de milho e de trigo, não observando diferenças na eficiência dessa redução pelos diferentes tipos de palha na superfície do solo.

West et al. (1991) constataram redução de $70 \%$ na perda de solo por erosão, em entressulcos, no sistema sem preparo em relação aos submetidos ao preparo convencional. Essa diferença foi atribuída ao teor de carbono orgânico e agregados estáveis em água, em maior quantidade no sistema sem preparo do solo.

Em um Argissolo Vermelho distrófico arênico do Rio Grande do Sul, Schäfer et al. (2001) não constataram diferenças nas perdas de solo em entressulcos entre os tratamentos com preparo convencional (convencional recentemente preparado e convencional com dois meses de consolidação) e entre os tratamentos sem preparo do solo (com palha e sem palha). Entretanto, em qualquer tratamento sem preparo do solo as perdas de solo em entressulcos foram significativamente menores do que em qualquer dos tratamentos em preparo convencional. Determinaram fator de erodibilidade do solo em entressulcos de $\mathrm{K}_{\mathrm{i}}=1,77 \times 10^{6} \mathrm{~kg} \mathrm{~s} \mathrm{~m}^{-4}$.

A erodibilidade expressa a suscetibilidade do solo ao processo erosivo. A diferença na erodibilidade de solos distintos ocorre por causa das condições intrínsecas desses solos, dadas pelas características e propriedades físicas, químicas e mineralógicas (Foster, 1982). A erodibilidade em entressulcos $\left(\mathrm{K}_{\mathrm{i}}\right)$ é uma medida da suscetibilidade do solo à desagregação pelo impacto das gotas de chuva (Alberts et al., 1995).

O objetivo deste trabalho foi avaliar em um Argissolo Vermelho distrófico típico a erosão hídrica em entressulcos, sob os sistemas de manejo sem preparo do solo (com resíduos culturais na superfície), em preparo convencional com solo descoberto (sem resíduos) e em preparo convencional com resíduos incorporados e determinar o fator de erodibilidade em entressulcos $\left(K_{i}\right)$ para utilização no modelo WEEP de predição da erosão hídrica do solo.

\section{Material e Métodos}

O trabalho foi realizado em área da Estação de Pesquisa e Produção Águas Belas, da Fundação Estadual de Pesquisa Agropecuária (Fepagro) da Secretaria de Ciência e Tecnologia do Estado do Rio Grande do Sul, localizada no Município de Viamão, região metropolitana de Porto Alegre, numa altitude de 52 metros. A área experimental localizou-se na porção inferior de uma pendente com declividade entre $8 \%$ e 19\%, cujo solo é classificado como Argissolo Vermelho distrófico típico (Embrapa, 1999).

Em julho de 1995, a área recebeu calcário para correção da acidez do solo, incorporado com preparo convencional. Logo a seguir foi feita semeadura de um consórcio de aveia (Avena sativa) + azevém (Lolium multiflorum). Esse procedimento inicial foi realizado com o objetivo de homogeneizar a área experimental. Ao final do ciclo das culturas de aveia+azevém, a área foi dividida em três faixas retangulares (de aproximadamente 20x30 m cada), com a maior dimensão no sentido do declive. Uma dessas faixas foi mantida com solo descoberto. Nas duas outras foi implantada uma sucessão de culturas, tendo-se semeado 
milho (Zea mays) em dezembro de 1995 e aveia em julho de 1996. Numa das faixas foi feito o preparo convencional do solo (uma aração com arado de discos e duas gradagens com grade niveladora de discos) e na outra a semeadura direta (sem preparo do solo). Em dezembro de 1996, ao final do ciclo da cultura da aveia, dentro de cada uma das três áreas, construíram-se seis parcelas em entressulcos, com dimensões de $0,75 \times 0,50 \mathrm{~m}$, com a maior dimensão no sentido do declive, delimitadas com chapas de metal. O delineamento experimental foi completamente casualizado. Em dezembro de 1996 foram aplicadas chuvas simuladas sobre as parcelas de erosão em entressulcos, com os seguintes tratamentos: solo descoberto (SD), com preparo convencional (uma aração + duas gradagens) realizado no sentido do declive; preparo convencional (CI) no sentido do declive, com a palha da cultura da aveia, anterior ao teste de campo, incorporada por ocasião do preparo do solo; sem preparo (SP): com a palha da cultura de aveia, anterior ao teste de campo, roçada e deixada na superfície.

Durante a aplicação de chuva simulada, a coleta dos dados em todos os tratamentos foi realizada conforme o modelo WEPP (Elliot et al., 1989). Utilizou-se o simulador de chuvas de braços rotativos (Cassol \& Guerra, 1978), para aplicação de chuva com intensidade planejada de $60 \mathrm{~mm} \mathrm{~h}^{-1}$, durante 70 minutos. A intensidade observada de chuva foi medida por pluviômetros localizados próximos da extremidade superior externa das parcelas experimentais. Durante a chuva, foi coletada toda a enxurrada proveniente das parcelas, utilizando-se potes de plástico colocados nas saídas das calhas coletoras. As taxas instantâneas de perda e a perda total de solo e água foram calculadas a partir dos potes com as amostras coletadas, antes e depois de serem secadas em estufa a $65^{\circ} \mathrm{C}$.

No modelo WEPP (Lane et al., 1987), a desagregação em entressulcos é modelada da seguinte maneira:

$D_{i}=K_{i} \quad I^{2} S_{f}$,

em que $D_{i}$ é a taxa de desagregação em entressulcos $\left(\mathrm{kg} \mathrm{m}^{-2} \mathrm{~s}^{-1}\right) ; \mathrm{K}_{\mathrm{i}}$ é o fator de erodibilidade do solo em entressulcos $\left(\mathrm{kg} \mathrm{s} \mathrm{m}^{-4}\right)$; I é a intensidade da chuva $\left(\mathrm{m} \mathrm{s}^{-1}\right)$; $\mathrm{S}_{\mathrm{f}}$ é o fator declividade (adimensional)

A equação que estima o fator declividade, que serve para ajustar a taxa de erosão em entressulcos em razão da declividade, é dada pela seguinte expressão (Elliot et al., 1989):

$\mathrm{S}_{\mathrm{f}}=1,05-0,85 \exp ^{(-4 \operatorname{sen} \theta)}$,

em que $\theta$ é o ângulo do declive (graus).

A erodibilidade do solo em entressulcos foi obtida pelo rearranjo da equação (1), obtendo-se a expressão $\mathrm{K}_{\mathrm{i}}=\mathrm{D}_{\text {imáx }} / \mathrm{I}^{2} \cdot \mathrm{S}_{\mathrm{f}}$, em que $\mathrm{D}_{\text {imáx }}$ é a taxa máxima de erosão em entressulcos $\left(\mathrm{kg} \mathrm{m}^{-2} \mathrm{~s}^{-1}\right)$.

A declividade das parcelas em entressulcos foi medida antes da realização dos testes. Houve variação significati- va na declividade das parcelas experimentais, pelo teste de Duncan a 5\% de probabilidade, em virtude dos diferentes formatos com que elas foram construídas. Nos tratamentos $\mathrm{SD}$ e CI, as parcelas apresentavam formato triangular da seção transversal da superfície do solo, com uma calha coletora central para a coleta de sedimentos desagregados e transportados na área em entressulcos. No tratamento SP, essas parcelas apresentavam formato retangular da seção transversal da superfície do solo, com a declividade natural do terreno, e a calha coletora situada na extremidade inferior da parcela. Os diferentes formatos de parcela não influenciam nos resultados (Reichert et al., 2001), desde que sejam referidos a uma mesma condição de declive. As perdas de solo foram então normalizadas com referência a uma mesma condição de declive e a uma mesma intensidade de chuva, utilizando-se a expressão apresentada por Cassol et al. (1999):

$P_{n}=P_{o}\left(\frac{I_{p}}{I_{o}}\right)^{2}\left(\frac{S_{f r}}{S_{f p}}\right)$,

em que $\mathrm{P}_{\mathrm{n}}$ é a perda de solo normalizada, $\mathrm{kg} ; \mathrm{P}_{\mathrm{o}}$ é a perda de solo observada, $\mathrm{kg} ; \mathrm{I}_{\mathrm{p}}$ é a intensidade de chuva planejada $\left(\mathrm{mm} \mathrm{h}^{-1}\right) ; \mathrm{I}_{\mathrm{o}}$ é a intensidade de chuva observada $\left(\mathrm{mm} \mathrm{h}^{-1}\right) ; \mathrm{S}_{\mathrm{fr}}$ é o fator declividade de referência; $\mathrm{S}_{\mathrm{fp}}$ é o fator declividade da parcela. No presente trabalho, considerando-se que a variação na intensidade das chuvas aplicadas não foi significativamente diferente da intensidade planejada, de $60 \mathrm{~mm} \mathrm{~h}^{-1}$, pelo teste de Duncan a $5 \%$ de probabilidade, o termo da expressão (3) que envolve a intensidade da chuva tornou-se igual a unidade. Para declividade de referência utilizou-se o valor de $45^{\circ}$ para o ângulo do declive, determinando-se os valores de $\mathrm{S}_{\mathrm{fr}}$ e de $\mathrm{S}_{\mathrm{fp}}$ pela expressão (2).

\section{Resultados e Discussão}

No tratamento com preparo convencional e solo descoberto (SD), as taxas de perda de água foram crescentes até aproximadamente $37 \mathrm{~min}$, e no tratamento com preparo convencional com palha incorporada (CI), perto de 54 min (Figura 1). Após esse tempo, as taxas tenderam a decrescer até o final dos testes. No tratamento sem preparo (SP), as taxas foram crescentes durante todo o período de aplicação da chuva simulada.

No tratamento SP, a cobertura da superfície do solo pela palha da aveia foi praticamente $100 \%$, e, consequientemente, houve grande proteção da su- 
perfície contra o impacto direto das gotas da chuva, provavelmente impedindo a formação de selo superficial. Além disso, a palha possivelmente reduziu a velocidade de escoamento da água, o que possibilitou maior infiltração de água no solo, e, em decorrência, menores taxas de perda de água em relação aos

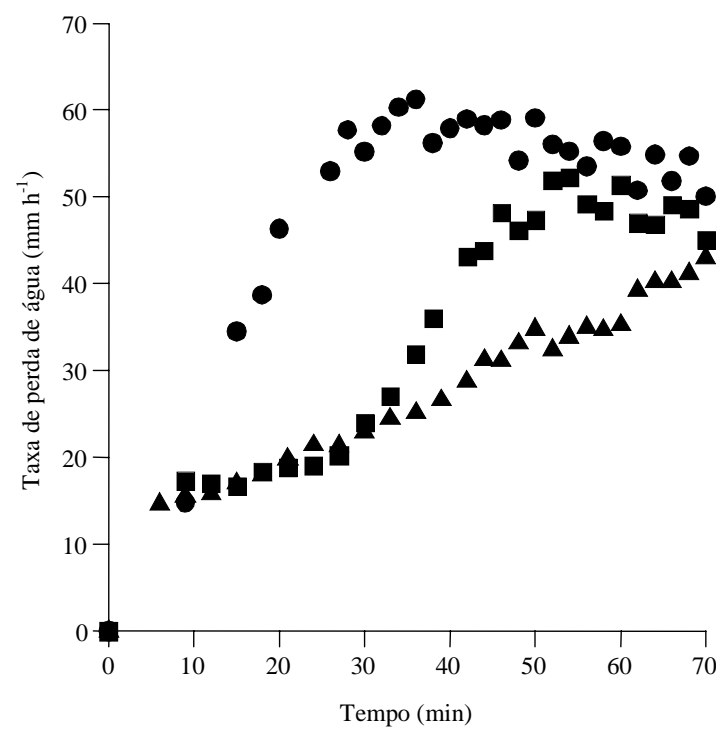

Figura 1. Taxa de perda de água em entressulcos, em razão do tempo de aplicação da chuva simulada, nos diferentes tratamentos ( $\bullet$ : preparo convencional com solo descoberto; : preparo convencional com palha incorporada; А: sem preparo). Média de seis repetições. outros tratamentos. Nos tratamentos SD e CI, sem cobertura do solo por palha no início dos testes, provavelmente ocorreu o selamento superficial, com o conseqüente aumento das taxas de perda de água.

Braida \& Cassol $(1996,1999)$ observaram que, com o solo descoberto ou com doses de palha de trigo e de milho de até $0,2 \mathrm{~kg} \mathrm{~m}^{-2}$, as taxas de perdas de água em entressulcos aumentavam inicialmente até um determinado tempo, a partir do qual tornavam-se estáveis, ao passo que doses de $0,4 \mathrm{e}$ $0,8 \mathrm{~kg} \mathrm{~m}^{-2}$ de palha de trigo e de milho elevaram as taxas de perdas de água durante os 90 min de aplicação de chuva simulada de intensidade de $67 \mathrm{~mm} \mathrm{~h}^{-1}$. Resultados semelhantes foram obtidos em laboratório por Lattanzi et al. (1974).

No tratamento SD ocorreu a maior perda total de água, em virtude da completa exposição da superfície do solo ao impacto das gotas da chuva, durante todo o período de chuva, com a possível formação de selamento superficial em um menor tempo (Tabela 1). Nesse tratamento, as maiores taxas instantâneas de perda de água, a partir dos 10 min de aplicação de chuva simulada, em relação aos outros tratamentos (Figura 1), proporcionaram maior perda total de água.

No tratamento CI houve tendência de maior perda total de água em relação ao tratamento SP, considerando os 70 min de aplicação de chuva simulada, embora não se tenha constatado diferença estatisticamente significativa entre os tratamentos (Tabela 1). Tal afirmação pode ser sustentada pelas taxas ins-

Tabela 1. Perda total de água e de solo e taxa de perda de solo em entressulcos, em razão do tipo de preparo e manejo do solo, pela aplicação de chuva simulada de $60 \mathrm{~mm} \mathrm{~h}^{-1}$ durante 70 minutos. Média de seis repetições ${ }^{(1)}$.

\begin{tabular}{lcccccc}
\hline Tratamento & $\begin{array}{c}\text { Perda total } \\
\text { de água } \\
(\mathrm{mm})\end{array}$ & $\begin{array}{c}\text { Perda total } \\
\text { de solo } \\
\text { observada } \\
(\mathrm{kg})\end{array}$ & $\begin{array}{c}\text { Declividade } \\
\text { das parcelas } \\
\left(\mathrm{m} \mathrm{m}^{-1}\right)\end{array}$ & $\begin{array}{c}\text { Fator de } \\
\text { ajuste do } \\
\text { declive } \mathrm{S}_{\mathrm{f}}^{(2)}\end{array}$ & $\begin{array}{c}\text { Perda de solo } \\
\text { normalizada } \\
\left(\mathrm{P}_{\mathrm{n}}\right)(\mathrm{kg})^{(3)}\end{array}$ & $\begin{array}{c}\text { Taxa de perda } \\
\text { de solo } \\
\left(\mathrm{kg} \mathrm{m}^{-2}\right)^{(4)}\end{array}$ \\
\hline $\begin{array}{l}\text { Preparo convencional com } \\
\text { solo descoberto }\end{array}$ & $55,55 \mathrm{a}$ & 0,654 & $0,352 \mathrm{~b}$ & 0,8248 & 0,793 & $2,115 \mathrm{a}$ \\
$\begin{array}{l}\text { Preparo convencional com } \\
\text { palha incorporada }\end{array}$ & $38,77 \mathrm{~b}$ & 0,761 & $0,464 \mathrm{a}$ & 0,8922 & 0,853 & $2,275 \mathrm{a}$ \\
\begin{tabular}{l} 
Sem preparo do solo \\
\hline
\end{tabular} & $30,94 \mathrm{~b}$ & 0,047 & $0,165 \mathrm{c}$ & 0,6068 & 0,077 & $0,205 \mathrm{~b}$ \\
\hline
\end{tabular}

${ }^{(1)}$ Médias seguidas por letras distintas diferem entre si a $5 \%$ de probabilidade pelo teste de Duncan. ${ }^{(2)} \mathrm{S}_{\mathrm{f}}=1,05-0,85$ e $\mathrm{e}^{(-4}$ sen $\left.\theta\right)$ em que e é a base do logaritmo natural; $\theta$ é o ângulo do declive, em graus. ${ }^{(3)} \mathrm{P}_{\mathrm{n}}=\mathrm{P}_{\mathrm{o}} \mathrm{x}\left(\mathrm{S}_{\mathrm{fr}} / \mathrm{S}_{\mathrm{fp}}\right)$, em que $\mathrm{P}_{\mathrm{n}}$ é a perda de solo normalizada; $\mathrm{P}_{\mathrm{o}}$ é a perda de solo observada; $\mathrm{S}_{\mathrm{fr}}$ é o fator declividade de referência $\left(\mathrm{S}_{\mathrm{fr}}=1,0\right.$ quando o ângulo do declive é de $\left.45^{\circ}\right) ; \mathrm{S}_{\mathrm{fp}}$ é o fator declividade da parcela. ${ }^{(4)} \mathrm{A}$ área da parcela experimental em entressulcos é de $0,375 \mathrm{~m}^{2}$. 
tantâneas de perda de água no tratamento CI, as quais são maiores a partir de aproximadamente $35 \mathrm{~min}$ de aplicação da chuva simulada (Figura 1).

A taxa de desagregação em entressulcos, considerada como sendo igual à taxa de perda de solo, foi crescente com o tempo de aplicação da chuva simulada (Figura 2). No tratamento SD, foi crescente até por volta dos 40 min de chuva, quando atingiu o ponto de máxima, com tendência a decrescer após esse tempo. No tratamento CI, a taxa foi crescente até atingir ponto de máxima, aproximadamente aos 59 min de chuva, a partir do qual também decresceu. No tratamento SP, as taxas de perdas de solo por erosão em entressulcos foram consideravelmente reduzidas, apresentando leve tendência a serem crescentes do início até o final do período de 70 min de chuva.

As taxas crescentes de perda de solo com o transcorrer da chuva até um certo período, nos tratamentos SD e CI (Figura 2), que estão relacionadas com o aumento das taxas de perda de água (Figura 1), podem ser explicadas pelo aumento da capacidade de transporte do fluxo laminar. Assim, as

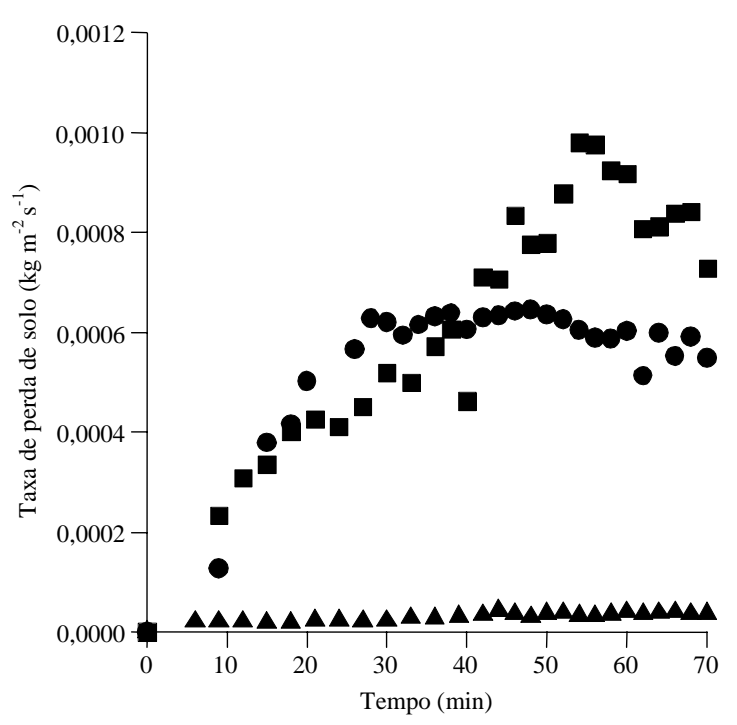

Figura 2. Taxa de perda de solo em entressulcos, em razão do tempo de aplicação da chuva simulada, nos diferentes tratamentos ( $\bullet$ : preparo convencional com solo descoberto; $\mathbf{\square}$ : preparo convencional com palha incorporada; А: sem preparo). Média de seis repetições. partículas desagregadas anteriormente, que não haviam sido transportadas por causa da baixa capacidade de transporte do fluxo laminar, são removidas. Em seguida o fluxo laminar passa a transportar somente as instantaneamente desagregadas, fato este que pode justificar as taxas decrescentes de perda de solo após certo tempo de chuva. Outra justificativa para o decréscimo dessas taxas diz respeito à limitação da erosão pela taxa de desagregação, em que, com o transcorrer do tempo de chuva, há redução da erodibilidade da camada superficial do solo, pela remoção seletiva das partículas mais erodíveis e pela formação de selamento superficial, conforme descrevem Moore \& Singer (1990).

A tendência de redução das taxas de erosão após período inicial de taxas crescentes, em parcelas sem cobertura do solo, também foi observada por Bradford et al. (1987), Rockenbach (1992) e Braida \& Cassol (1996, 1999).

Não houve diferença significativa na perda total de solo entre os tratamentos SD e CI (Tabela 1). No tratamento SP ocorreu perda total de solo em entressulcos significativamente menor do que nos demais tratamentos, em decorrência do efeito da cobertura da superfície com palha na redução significativa da desagregação do solo. West et al. (1991) também observaram tendência semelhante em relação ao sistema de semeadura sem preparo do solo. Rockenbach (1992) e Braida \& Cassol (1999) constataram que o aumento da quantidade de palha na superfície do solo reduziu as perdas totais de solo nos entressulcos.

A erodibilidade do solo em entressulcos foi calculada a partir das taxas de desagregação de solo do tratamento SD (Figura 2). Nesse tratamento a variação nas taxas de desagregação em relação ao tempo de aplicação de chuva simulada foi melhor ajustada pela seguinte expressão:

$\mathrm{D}_{\mathrm{i}}=1,306 \times 10^{-5} \mathrm{t}+2,613 \times 10^{-6} \mathrm{t}^{2}-6,485 \times 10^{-7} \mathrm{t}^{2,5}+$ $3,919 \times 10^{-8} \mathrm{t}^{3}, \mathrm{r}^{2}=0,967$,

em que $\mathrm{D}_{\mathrm{i}}$ é a taxa de desagregação em entressulcos $\left(\mathrm{kg} \mathrm{m}^{-2} \mathrm{~s}^{-1}\right)$ e t é o tempo da chuva ( $\left.\mathrm{min}\right)$.

$\mathrm{O}$ ponto de máximo valor de $\mathrm{D}_{\mathrm{i}}$ foi obtido pela diferenciação da expressão (4). O valor de t para o qual a primeira derivada de $\mathrm{D}_{\mathrm{i}}$ em relação a t é igual a zero, corresponde ao valor de t em que ocorre a maior taxa de desagregação. Esse valor 
$\mathrm{t}=$ 40,086454 min), substituído na expressão (4), retorna o máximo valor de $\mathrm{D}_{\mathrm{i}}$, que é de $6,49 \times 10^{-4} \mathrm{~kg} \mathrm{~m}^{-2} \mathrm{~s}^{-1}$ (Figura 2). A intensidade da chuva simulada (I) aplicada é de $1,667 \times 10^{-5} \mathrm{~m} \mathrm{~s}^{-1}$ $\left(60 \mathrm{~mm} \mathrm{~h}^{-1}\right)$. O fator declividade do solo $\left(\mathrm{S}_{\mathrm{f}}\right)$, calculado pela equação (2), a partir da declividade média das parcelas em entressulcos com solo descoberto $\left(0,352 \mathrm{~m} \mathrm{~m}^{-1}\right)$, é de 0,8248 (Tabela 1$)$. Dessa forma, pelo rearranjo da expressão (1), obtém-se o valor de $\mathrm{K}_{\mathrm{i}}=\mathrm{D}_{\mathrm{i}} /\left(\mathrm{I}^{2} \times \mathrm{S}_{\mathrm{f}}\right) . \mathrm{O}$ valor do fator de erodibilidade do solo em entressulcos $\left(\mathrm{K}_{\mathrm{i}}\right)$ é de $2,83 \times 10^{6} \mathrm{~kg} \mathrm{~s} \mathrm{~m}^{-4}$ no Argissolo em estudo.

Rockenbach (1992), num Podzólico VermelhoAmarelo de textura franco-arenosa do Rio Grande do Sul, determinou erodibilidade em entressulcos de $3,35 \times 10^{6} \mathrm{~kg} \mathrm{~s} \mathrm{~m}^{-4}$. Braida \& Cassol (1996), por sua vez, em Podzólico Vermelho-Escuro de textura mais arenosa que o primeiro, determinaram erodibilidade de $5,10 \times 10^{6} \mathrm{~kg} \mathrm{~s} \mathrm{~m}^{-4}$. O solo do presente trabalho assemelha-se ao solo estudado por Rockenbach (1992), porém com teores de argila superiores tanto com respeito ao solo estudado por Rockenbach (1992) quanto ao utilizado por Braida \& Cassol (1996). Essa característica pode justificar a menor erodibilidade do solo em entressulcos encontrada no presente trabalho. Já Schäfer et al. (2001) determinaram em um Argissolo Vermelho distrófico arênico do Rio Grande do Sul fator de erodibilidade do solo em entressulcos de $1,77 \times 10^{6} \mathrm{~kg} \mathrm{~s} \mathrm{~m}^{-4}$, inferior ao obtido no presente estudo. Tal resultado pode ser devido ao fato de esses autores terem trabalhado com solo sob recente preparo convencional após ser utilizado durante oito anos em sistema de plantio direto. No presente trabalho, o fator de erodibilidade em entressulcos foi determinado em solo mantido descoberto durante um ano, período em que foi submetido a preparo convencional, semelhante aos estudos de Elliot et al. (1989), para obtenção dos parâmetros do modelo WEPP. A uniformização da metodologia e a clara definição da aplicabilidade do fator erodibilidade do solo em entressulcos devem ser bem estabelecidas quando se deseja obter um valor aplicável desse parâmetro.

\section{Conclusões}

1. Em sistemas de semeadura sem preparo do solo, as perdas de água nas áreas em entressulcos são consideravelmente reduzidas em relação ao solo descoberto, porém não são menores do que quando há preparo convencional do solo com incorporação de resíduos.

2. As taxas de perdas de solo por erosão são reduzidas em torno de $90 \%$ pelo sistema sem preparo do solo em relação ao solo descoberto e ao preparo convencional com incorporação de resíduos.

3. Para aplicação do modelo WEPP, de predição de erosão hídrica, o valor do fator de erodibilidade do Argissolo Vermelho distrófico típico em entressulcos $\left(\mathrm{K}_{\mathrm{i}}\right)$ é de $2,83 \times 10^{6} \mathrm{~kg} \mathrm{~s} \mathrm{~m}^{-4}$.

\section{Agradecimentos}

Aos colegas do curso de pós-graduação do segundo autor e aos funcionários da estação experimental da Fepagro de Viamão, pelo auxílio na realização dos testes de campo; à Fepagro, pela cessão do simulador de chuvas e da área experimental; à UFRGS, pelo apoio material e laboratorial.

\section{Referências}

ALBERTS, E. E.; NEARING, M. A.; WELTZ, M. A.; RISSE, L. M.; PIERSON, F. B.; ZHANG, X. C.; LAFLEN, J. M.; SIMANTON, J. R. Soil component. In: FLANAGAN, D. C.; NEARING, M. A. (Ed.). Water erosion prediction project: hillslope profile and watershed model documentation. West Lafayette: United States Department of Agriculture/National Soil Erosion Research Laboratory, 1995. p. 7.1-7.47 (NSERL Report, 10).

BRADFORD, J. M.; FERRIS, J. E.; REMLEY, P. A. Interrill soil erosion processes - I: effect of surface sealing on infiltration, runoff and soil splash detachment. Soil Science Society of America Journal, Madison, v. 51, n. 6, p. 1566-1571, Nov./Dec. 1987.

BRAIDA, J. A.; CASSOL, E. A. Erodibilidade em sulcos e em entressulcos de um Podzólico Vermelho-Escuro franco-arenoso. Revista Brasileira de Ciência do Solo, Campinas, v. 20, n. 1, p. 127-134, jan./abr. 1996.

BRAIDA, J. A.; CASSOL, E. A. Relações da erosão em entressulcos com o tipo e com a quantidade de resíduo vegetal na superfície do solo. Revista Brasileira de Ciência do Solo, Viçosa, MG, v. 23, n. 3, p. 699-709, jul./ set. 1999. 
CASSOL, E. A.; GUERRA, M. Calibração do primeiro aparelho simulador de chuvas de braços rotativos do Estado do Rio Grande do Sul. In: ENCONTRO NACIONAL DE PESQUISA SOBRE CONSERVAÇÃO DO SOLO, 2., 1978, Passo Fundo. Anais... Passo Fundo: EmbrapaCNPT, 1978. p. 29-39.

CASSOL, E. A.; LEVIEN, R.; LIER, Q. J. van; BADELUCCI, M. P. Infiltração de água e perdas de água e solo por erosão influenciadas por diferentes métodos de melhoramento da pastagem nativa gaúcha. Revista Brasileira de Ciência do Solo, Viçosa, MG, v. 23, p. 923931, 1999

ELLIOT, W. J.; LIEBENOW, A. M.; LAFLEN, J. M. KOHL, K. D. A compendium of soil erodibility data from WEPP cropland soil field erodibility experiments 1987 \& 88. West Lafayette: Ohio State University/United States Department of Agriculture, 1989. p. A2-A25 (NSERL Report, 3).

ELLISON, W. D. Soil detachment and transportation. Soil Conservation, Washington, v. 11, n. 8, p. 179-190, 1946.

ELLISON, W. D. Soil erosion studies - part I. Agricultural Engineering, St. Joseph, v. 28, n. 4, p. 145-146, Apr. 1947a.

ELLISON, W. D. Soil erosion studies - part II: soil detachment hazard by raindrop splash. Agricultural Engineering, St. Joseph, v. 28, n. 5, p. 197-201, May $1947 b$.

ELLISON, W. D. Soil erosion studies - part III: effects of soil erosion on infiltration and surface runoff. Agricultural Engineering, St. Joseph, v. 28, n. 6, p. 245-248, June $1947 c$.

ELLISON, W. D. Soil erosion studies - part IV: soil erosion, soil loss, and some effects of soil erosion. Agricultural Engineering, St. Joseph, v. 28, n. 7, p. 297-300, July 1947 d.

ELLISON, W. D. Soil erosion studies - part V: soil transportation in the splash process. Agricultural Engineering, St. Joseph, v. 28, n. 8, p. 349-351, 353, Aug. 1947e.

ELLISON, W. D.; ELLISON, O. T. Soil erosion studies part VI: soil detachment by surface flow. Agricultural Engineering, St. Joseph, v. 28, n. 9, p. 402-405, 408, Sept. 1947a.

ELLISON, W. D.; ELLISON, O. T. Soil erosion studies part VII: soil transportation by surface flow. Agricultural Engineering, St. Joseph, v. 28, n. 10, p. 442-444, 450, Oct. $1947 b$.
EMBRAPA. Centro Nacional de Pesquisa de Solos (Rio de Janeiro, RJ). Sistema brasileiro de classificação de solos. Brasília: Embrapa-SPI/Embrapa-CNPS, 1999. 412 p.

FLANAGAN, D. C.; ASCOUGH II, J. C.; NICKS, A. D.; NICKS, A. D.; NEARING, M. A.; LAFLEN, J. M. Overview of the WEPP erosion prediction model. In: FLANAGAN, D. C.; NEARING, M. A. (Ed.). Water erosion prediction project: hillslope profile and watershed model documentation. West Lafayette: United States Department of Agriculture/National Soil Erosion Research Laboratory, 1995. p. 1.1-1.12 (NSERL Report, 10).

FOSTER, G. R. Modeling the erosion process. In: HAAN, C. T. (Ed.). Hydrologic modeling of small watersheds. St. Joseph: American Society of Agricultural Engineers, 1982. p. 297-380. (ASAE Monograph, 5).

FOSTER, G. R.; YOUNG, R. A.; RÖMKENS, M. J. M.; ONSTAD, C. A. Processes of soil erosion by water. In: FOLLETT, R. F.; STEWART, B. A. (Ed.). Soil erosion and crop productivity. Madison: American Society of Agronomy/Crop Science Society of America/Soil Science Society of America, 1985. p. 137-162.

LANE, L. J.; FOSTER, G. R.; NICKS, A. D. Use of fundamental erosion mechanics in erosion prediction. St. Joseph: American Society of Agricultural Engineers, 1987. (ASAE Paper, 87-2540).

LATTANZI, A. R.; MEYER, L. D.; BAUMGARDNER, M. F. Influences of mulches rate and slope steepness on interril erosion. Soil Science Society of America Proceedings, Madison, v. 38, n. 6, p. 946-950, Nov./Dec. 1974.

MANNERING, J. V.; MEYER, L. D. The effects of various rates of surface mulch on infiltration and erosion. Soil Science Society of America Proceedings, Madison, v. 27, n. 1, p. 84-86, Jan./Feb. 1963.

MEYER, L. D.; FOSTER, G. R.; RÖMKENS, M. J. M. Source of soil eroded by water from upland slopes. In: ESTADOS UNIDOS. Department of Agriculture. Agriculture Research Service. Present and prospective technology for predicting sediment yields and sources. Washington, 1975. p. 177-189. (USDA. ARS-S, 40).

MOORE, D. C.; SINGER, M. J. Crust formation effects on soil erosion processes. Soil Science Society of America Journal, Madison, v. 54, n. 4, p. 1117-1123, Jul./Aug. 1990

REICHERT, J. M.; SCHÄFER, M. J.; ELTZ, F. L. F.; NORTON, L. D. Erosão em sulcos e entressulcos em ra- 
zão do formato de parcela em Argissolo Vermelho-Amarelo arênico. Pesquisa Agropecuária Brasileira, Brasília, v. 36, n. 7, p. 965-973, jul. 2001.

ROCKENBACH, C. A. Erosão em entressulcos sob diferentes coberturas por resíduos de trigo em um solo Podzólico Vermelho Amarelo sob chuva simulada. 1992. 108 f. Dissertação (Mestrado em Ciência do Solo) Universidade Federal do Rio Grande do Sul, Porto Alegre, 1992.
SCHÄFER, M. J.; REICHERT, J. M.; REINERT, D. J.; CASSOL, E. A. Erosão em entressulcos em diferentes preparos e estados de consolidação do solo. Revista Brasileira de Ciência do Solo, Viçosa, MG, v. 25, n. 2, p. 431441, abr./jun. 2001.

WEST, L. T.; MILLER, W. P.; LANGDALE, G. W.; BRUCE, R. R.; LAFLEN, J. M.; THOMAS, A. W. Cropping system effects on interrill soil loss in the Georgia Piedmont. Soil Science Society of America Journal, Madison, v. 55, n. 2, p. 460-466, Mar./Apr. 1991. 